\title{
INFECCIONES DE PRÓTESIS TOTAL DE RODILLA
}

\author{
TOTAL KNEE PROSTHESIS INFECTIONS
}

\author{
Girón-Cornelio Melvin Frank ${ }^{\text {1, a, b }}$ \\ 1. Universidad Nacional San Luis Gonzaga de Ica, Perú. \\ a. Médico Asistente del servicio de Ortopedia y Traumatología del Instituto Nacional de Salud \\ del Niño Breña - Lima - Perú. \\ b. Médico residente de Ortopedia y traumatología Hospital Augusto Hernández Mendoza Es \\ salud Ica. \\ c. Médico Cirujano.
}

doi: https://doi.org/10.35563/rmp.v8i1.14

\section{Correspondencia:}

Girón Cornelio Melvin Frank. Número de celular: 51946868293 Correo Electrónico:

melvin_ma67@hotmail.com

Domicilio: Casuarinas D - 29 - Ica

\section{Contribuciones De Autoría:}

GCMK: Contribuciones en la concepción y diseño del manuscrito, recolección, análisis e interpretación de los datos, redacción y revisión crítica del contenido del manuscrito y aprobación final del artículo.

Conflicto De Intereses: No declarados.

Financiamiento: Autofinanciado.

\section{Como Citar}

Girón-Cornelio Melvin Frank. Infecciones de prótesis total de rodilla. Rev méd panacea 2019;8(1): 46-54

Recibido: 03 - 03 - 2019

Aceptado: 20 - 04 - 2019

Publicado: 23 - 04 - 2019

\section{RESUMEN}

Objetivo: realizar una revisión bibliográfica y actualización sobre infección de prótesis total de rodilla. Materiales y métodos: : Es un Estudio bibliométrico, descriptivo transversal realizado mediante búsquedas bibliográficas en pubmed, NCBI, UP TO DATE, y revistas virtuales de Ortopedia y Traumatología del Perú e internacionales. Se seleccionó y consultó el material bibliográfico que tuviera información sobre infección de prótesis total de rodilla. Se excluyó la bibliografía sin relación con el tema y muy antigua. No hubo límites en el idioma. Los artículos seleccionados se clasificaron por relevancia, actualidad y localización. Desarrollo y discusión: La infección de prótesis de rodilla tiene una incidencia entre el 1 a $3 \%$ en prótesis primaria y 3.5 a $5 \%$ en prótesis de revisión, siendo los principales factores de riesgo principales, artritis reumatoide, cirugía previa, edad avanzada, sexo femenino, obesidad, desnutrición, diabetes e inmunodeficiencias, el diagnóstico es un reto para el médico, los cocos Gram positivos son los gérmenes más frecuentes, llegando a ser el $75 \%$ del total, el objetivo principal del tratamiento es erradicar la infección, el tratamiento quirúrgico debe ser agresivo y oportuno, es necesario recibir largos periodos de antibióticos sistémicos a fin de evitar cirugías radicales como la artrodesis y amputación. Conclusiones: la infección de prótesis de rodilla es la complicación más temida, tiene un diagnostico difícil y cuyo manejo demanda largos periodos de incapacidad, estancia hospitalaria, antibióticos de amplio espectro y cuantiosas perdida económicas la entidad prestadora de servicios de salud.

Palabras clave: Prótesis total de rodilla, infección, epidemiologia, tratamiento.

\section{ABSTRACT}

Objective: to perform a literature review and update on total knee prosthesis infection. Materials and methods: This is a bibliometric, cross-sectional descriptive study conducted through bibliographic searches in pubmed, NCBI, UP TO DATE, and virtual journals of Orthopedics and Traumatology of Peru and international. The bibliographic material that had information on total knee prosthesis infection was selected and consulted. The bibliography unrelated to the subject and very old was excluded. There were no limits in the language. The selected articles were classified by relevance, actuality and location. Development and discussion: Infection of knee prosthesis has an incidence between 1 to $3 \%$ in primary prostheses and 3.5 to $5 \%$ in revision prostheses, being the main risk factors, rheumatoid arthritis, previous surgery, advanced age, sex female, obesity, malnutrition, diabetes and immunodeficiencies, the diagnosis is a challenge for the doctor, Gram positive cocci are the most frequent germs, reaching $75 \%$ of the total, the main objective of the treatment is to eradicate the infection, the treatment surgical should be aggressive and timely, it is necessary to receive long periods of systemic antibiotics in order to avoid radical surgeries such as arthrodesis and amputation. Conclusions: knee prosthesis infection is the most feared complication, it has a difficult diagnosis and its management demands long periods of disability, hospital stay, broad spectrum antibiotics and large economic losses the health service provider entity.

Keywords: Total knee prosthesis, infection, epidemiology, treatment. 
Equipo quirúrgico Hospital Augusto Hernández Mendoza Es salud, Ica - Perú.

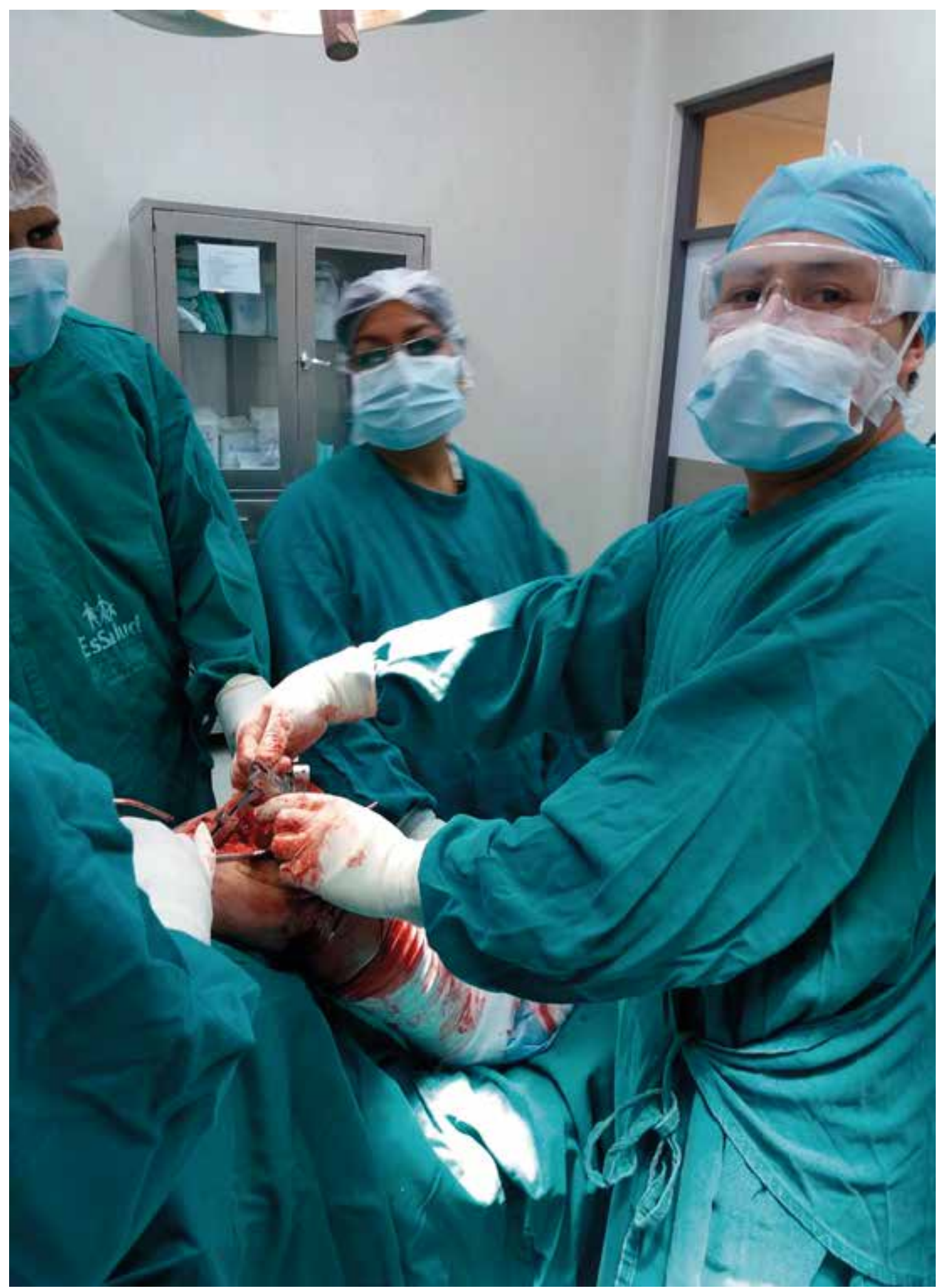

Realizando una artroplastia total de rodilla primaria.

De izquierda a derecha: Dr. Emerson Monroy Coacalla, Lic. Juana Rodríguez, Dr. Melvin Frank Girón Cornelio. 


\section{INTRODUCCIÓN}

La artroplastia total de rodilla (ATR) es sin duda uno de los procedimientos quirúrgicos con la más alta tasa de éxitos. La ATR ayuda sobremanera a optimizar la función y alivio del dolor, con lo que mejora la calidad y estilo de vida de los pacientes. Por esta razón, la cantidad de artroplastias primarias y de revisión están aumentando considerablemente. En los últimos años, se han producido muchas mejorías a nivel de implantes y técnicas, de hecho ahora cabe esperar una supervivencia del implante superior al 95\% a los 10 años, pero a pesar de eso aún existen controversias sobre diseño, plataformas móviles, reemplazo patelar, componentes no cementados y uso de artroplastias uni compartimentales $(1,2)$.

Para mejorar las limitaciones de los modelos tipo bisagra, Morgan y Freeman diseñan en 1968 la primera prótesis de rodilla con el componente femoral metálico (cóndilo) sobre una base de polietileno a modo de inserto, modelo con el que nacen varios principios de biomecánica aplicado aun en la actualidad, la constricción de la prótesis y balance ligamentario deben ser adecuados para conducir y transmitir las fuerzas a la interfaz hueso implante, así como mantener una amplia superficie de contacto entre los componentes deslizantes, para tener una adecuada distribución de las tensiones, eligiendo lo que se conoce ahora como el par de fricción plástico-metal, la técnica de implantación debe ser sencilla, reproducible y debe lograr como mínimo $90^{\circ}$ de flexión $(2,3)$.

La cirugía de reemplazo articular tiene varios riesgos, dentro de ellos tenemos, complicaciones de anestesia, complicaciones hemorrágicas, complicaciones infecciosas, complicaciones por transfusión sanguínea, alergias a componentes metálicos y cemento, lesiones arteriales, lesiones nerviosas,

Rigidez de la rodilla y pérdida de movimiento en la rodilla, problemas protésicos y falla del implante $(2,3)$.

Pese a denodados esfuerzos para evitar esta temida complicación, las infecciones afectan al $0.5 \%$ a $1.9 \%$ en caso de prótesis total de rodilla primaria y en $8 \%$ a $10 \%$ de las prótesis de revisión, estas puede ser en el post operatorio inmediato, posterior al alta del paciente, e incluso meses o años después, la colonización de germen se da por dos vías que son inoculación directa en el momento de la cirugía y la vía hematógena (4).

El pronóstico de los pacientes que presentan una infección de prótesis de rodilla, depende del diagnóstico precoz, características clínicas y manejo adecuado, así como la virulencia del germen, y la disponibilidad de recursos, medico quirúrgicos. (5).

\section{METODOLOGÍA}

Es un Estudio bibliométrico, descriptivo transversal realizado mediante búsquedas bibliográficas en pubmed, NCBI, UP TO DATE, y revistas virtuales de Ortopedia y Traumatología del Perú e internacionales. Se seleccionó y consultó el material bibliográfico que tuviera información sobre infección de prótesis total de rodilla. Se excluyó la bibliografía sin relación con el tema y muy antigua. No hubo límites en el idioma. Los artículos seleccionados se clasificaron por relevancia, actualidad y localización.

\section{DESARROLLO Y DISCUSIÓN}

Definición: Hay muchas definiciones de infección de prótesis de rodilla. Tsukayama las divide teniendo como parámetro el tiempo entre la cirugía y la presentación clínica.

\section{Infección posquirúrgica precoz (IPP):}

Aparece en el $1^{\circ}$ mes tras la cirugía. Hay síntomas y signos locales (dolor, eritema, tumefacción) asociados en muchos casos a infección del sitio quirúrgico (ISQ). La ISQ que se deja evolucionar sin cirugía más de 1 mes, pasa a considerarse una infección crónica. Un Liquido sinovial > 27.800 leucocitos/ $\mu \mathrm{L}$ y > $89 \%$ neutrófilos es predictivo de IPP de rodilla $(6,7,9)$.

\section{Infección posquirúrgica tardía o crónica (IPT):}

Se diagnostica desde el segundo mes tras la cirugía hasta 1-2 años después. Evolución lenta con dolor ondulante y persistente durante meses, asociado a escasos signos de flogosis, a febril. Pudiendo presentar derrame articular, abscesos y fistulización $(6,7,9)$.

\section{Infección aguda hematógena (IAH):}

Cuadro clínico agudo, con fiebre y flogosis en una prótesis previamente asintomática (indolora) y funcional durante largo tiempo (> 1-2 años), atribuidos a siembra hematógena de un foco distante concomitante o reciente (ITU, neumonía, bacteriemia, endocarditis, etc.). El 0,3\% de las bacteriemias van a colonizar los implantes, cuando el germen es Staphylococcus aureus este riesgo aumenta al $30 \%(6,7,9)$.

Infección denominada "cultivos intra operatorios positivos" (CIOP):

El cirujano interviene para recambiar una prótesis dolorosa, sin signos de infección, se toman cultivos "por protocolo" y se recambia la prótesis.

Estas se presentan con una frecuencia de: $50 \%$ IPT, 35\% IPP, $10 \%$ IHA y $5 \% \operatorname{CIOP}(6,7,9)$.

Epidemiologia: la incidencia de infección varía entre 1 a $2 \%$ en prótesis primarias y 3.5 a $5 \%$ en prótesis de revisión. Siendo los principales factores de riesgo, una cirugía previa, edad avanzada, sexo femenino, artritis reumatoide, obesidad, diabetes e inmunodeficiencias (8, 9).

La práctica de una cirugía protésica ha supuesto uno de los avances médicos más significativos en las últimas décadas. El advenimiento de nueva tecnología, el incremento de la expectativa de vida y aumento de la población longeva con patologías propias de la edad, han incrementado el número de pacientes sometidos a este procedimiento quirúrgico. La implantación de una prótesis de cadera, rodilla y, en menor grado, de hombro y otras articulaciones es ahora un procedimiento habitual en la mayoría de centros hospitalarios. La infección es su principal complicación. Esta complicación supone una desgracia para el paciente y un caso complejo además de un elevado costo para el sistema de salud. Un número elevado de estos pacientes pierden su prótesis y son sometidos a reiteradas intervenciones, largos periodos de estancia hospitalaria y tratamiento 
antibiótico prolongado $(2,5)$.

Diagnóstico: El diagnóstico se basa en la sospecha clínica, y debe ser precoz en las IPP e IHA y siendo difícil en las ICT.

Los exámenes auxiliares como la VSG (>30 m/h) cuya sensibilidad es 0,8 y especificidad, 0,6-0,7; PCR sinovial $(>6.9 \mathrm{mg} / \mathrm{Dl}$ ) cuya sensibilidad y especificidad es mayor $\mathrm{y}$ la de ambas pruebas conjuntamente superan el 0,9; sin embargo su valor es poco fiable en presencia de enfermedades inflamatorias crónicas, que causan falsos positivos (valor predictivo positivo [VPP] 0,75). En cambio, cuando es negativa es poco probable la presencia de una ICT (valor predictivo negativo [VPN] $0,99)(4,5,6,10)$.

Las radiografías simples no son de ayuda en los primeros 6 meses, pero luego pueden empezar a evidenciar radio luminiscencia de la interface cemento - hueso, valorable cuando es mayor a $2 \mathrm{~mm}$, osteólisis y modificación de los elementos protésicos, en presentación temprana supone ICT. La presencia de reacción perióstica es más específica de Infección $(5,6,7)$.

La gammagrafía ósea con 99mTc difosfonatos de metileno (MDP) no es de ayuda durante el primer año post cirugía $y$, además, es una prueba con baja especificidad. La gammagrafía de referencia es la de leucocitos marcados con $111 \mathrm{ln}$, teniendo una sensibilidad del $80 \%$, para casos de prótesis micro porosas la captación de médula ósea desplazada da falsos positivos. Mejora su especificidad cuando se hace conjuntamente con 99mTc con coloide de sulfuro BMS debido a la captación selectiva de la medula ósea (sensibilidad el $80 \%$, especificidad el 94\%) $(4,5)$.

De las técnicas recientes la gammagrafía con anticuerpos antigranulocitos $(99 \mathrm{mTc}$ con anticuerpos monoclonales anti-NCA-90) y la tomografía por emisión de positrones con fludeoxiglucosa $18 \mathrm{~F}$, destacan pero no aportan ventajas significativas $(7,10)$.

Tanto la tomografía computarizada (TC) como la resonancia magnética $(\mathrm{RM})$ no resultan útiles para excluir la infección protésica $(5,7)$.

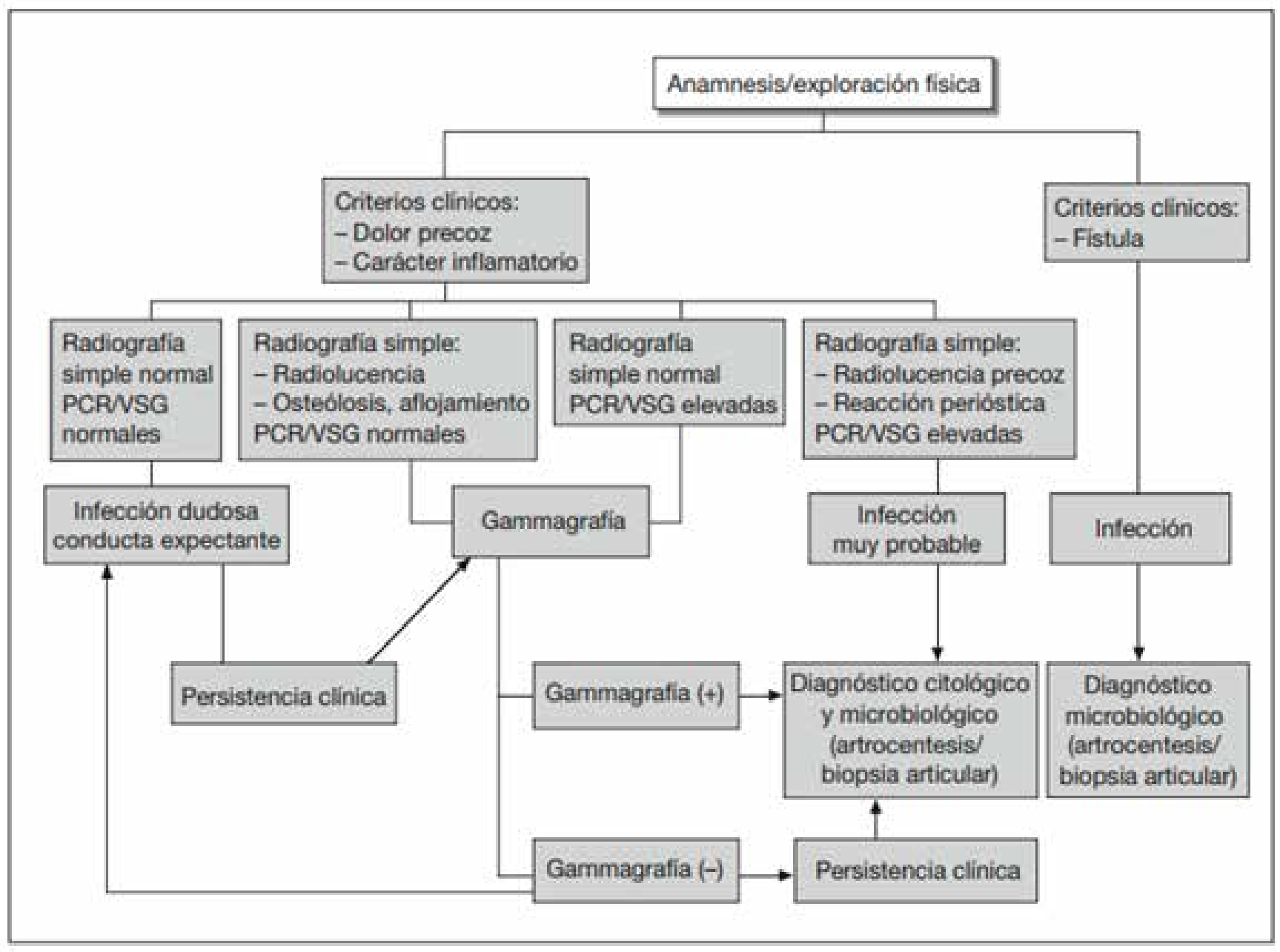

Imagen 1: Algoritmo diagnóstico.

Recuperado de: Javier Ariza, Gorane Euba y Óscar Murillo "Infecciones relacionadas con las prótesis articulares" Enferm Infecc Microbiol Clin 2008; 26(6):380-90 Pág. 384. 
Los cultivos secreción fistulosa no son tan fiables, excepto sean de aparición reciente y se aísle a S. aureus. La punción articular se debe considerar y se debe hacer cuando se sospecha de ICT. Se debe hacer tinción Gram, cultivo y recuento celular del líquido articular, siendo el punto de corte respecto del aflojamiento aséptico cuando hay más de 1.700 leucocitos/l o más del $65 \%$ de polimorfo nucleares, valor muy por debajo del habitualmente utilizado en el diagnóstico de artritis séptica (sensibilidad del 94-97\%, especificidad del 88-98\%); otros tiene el punto de corte en más de 3.000 leucocitos/l. La sensibilidad del Gram es menor al 25\% mientras que del cultivo oscila de $45-86 \%$. Sin embargo, la especificidad es elevada (88-97\%) $(5,6,7,10)$.

Es preferible realizar un diagnóstico pre quirúrgico, toda vez que se prepara el espaciador impregnado con antibiótico ideal, además de tener una cobertura antibiótica optima en el post operatorio inmediato, a veces, la presencia de una bacteria multi resistente comporta una modificación del planteamiento quirúrgico $(7,10,18)$.

Tabla 1: Sensibilidad y especificidad de las diferentes pruebas diagnósticas en las infecciones crónicas de prótesis articulares

\begin{tabular}{|c|c|c|c|c|}
\hline Pruebas & $\begin{array}{c}\text { Sensibilidad } \\
(\%)\end{array}$ & $\begin{array}{c}\text { Especificidad } \\
(\%)\end{array}$ & VPP (\%) & VPN (\%) \\
\hline \multicolumn{5}{|l|}{ Preoperatorias } \\
\hline \multicolumn{5}{|l|}{ Hematológicas } \\
\hline VSG & 80 & $60-70$ & 58 & 95 \\
\hline $\mathrm{PCR}^{*}$ & 96 & 92 & 74 & 99 \\
\hline VSG y $P C R^{*}$ & $>90$ & $>90$ & 83 & 99 \\
\hline \multicolumn{5}{|l|}{ Imagen } \\
\hline Gammagrafía 99Tc & 100 & $5-23$ & 30 & 100 \\
\hline Gammagrafía Leu 111ln & 80 & 60 & - & - \\
\hline Gammagrafía Leu 111ln + 99Tc sulfuro coloic & 80 & 94 & - & - \\
\hline PET & 90 & $55-89$ & - & - \\
\hline \multicolumn{5}{|l|}{ Muestras articulares } \\
\hline Líquido articular-Citología & $94-100$ & $88-98$ & 91 & 90 \\
\hline Líquido articular-Cultivo*** & $45-86$ & $88-97$ & 67 & 98 \\
\hline Biopsia articular-Cultivo*** & $70-85$ & $>90$ & 70 & 94 \\
\hline \multicolumn{5}{|l|}{ Operatorias } \\
\hline Cortes congelados (5-10 PMN/cc) & $67-80$ & $>90$ & 74 & 96 \\
\hline Cultivo positivo & $65-94$ & 97 & 77 & \\
\hline
\end{tabular}

Leu In: leucocitos marcados con indio; PCR: proteína C reactiva; PET: tomografía por emisión de positrones; PMN: polimorfo nucleares; Tc: tecnecio; VPN: valor predictivo negativo; VPP: valor predictivo positivo; VSG: velocidad de sedimentación globular.

* Especificidad y VPP con exclusión de pacientes con enfermedades inflamatorias crónicas.

** La negatividad de esta prueba combinada no excluye la posibilidad de una infección.

*** Cifras en función de la toma previa de antibióticos.

Tabla 01: Sensibilidad de métodos diagnósticos.

Recuperado de: Javier Ariza, Gorane Euba y Óscar Murillo "Infecciones relacionadas con las prótesis articulares" Enferm Infecc Microbiol Clin 2008; 26(6):380-90 Pág. 386. 


\section{FACTORES DE RIESGO:}

Enfermedades subyacentes como la «artritis reumatoide» tienen una tasa de infección mayor que la artrosis. Los pacientes con artritis reumatoide tienen más riesgo a desarrollar una infección tardía por vía hematógena y tienen más posibilidades de padecer bacteriemias e infecciones de tejidos blandas, debido al estado deteriorado de la fagocitosis e inmunodepresión. También tienen la piel más delgada y asociada a vasculitis, favoreciendo que los microorganismos alcancen la articulación. $(5,9)$.

Patologías generales como la diabetes, el alcoholismo, la insuficiencia renal crónica, el cáncer o cualquier otra que comprometa el sistema inmunitario del paciente, ocasionan un incremento del número de infecciones. La malnutrición del paciente, influye en el desarrollo de infección profunda; ocurren complicaciones en la cicatrización de la herida más frecuentes en pacientes con malnutrición, que viene indicada por una tasa de linfocitos menor de $1.500 \mathrm{~mm} 3(1,52103 / \mathrm{l})$ o un nivel de albúmina sérica menor de $3,5 \mathrm{~g} / \mathrm{dl}(35 \mathrm{~g} / \mathrm{l}$ ) o una transferrina sérica menor de $226 \mathrm{mg} / \mathrm{dl}(2,26 \mathrm{~g} / \mathrm{l})(5,9$, 11).

Otros factores de riesgo asociados con infección de prótesis son: haber sufrido una infección "superficial" postoperatoria de la herida quirúrgica, sin compromiso evidente de la prótesis (odds ratio [OR]: 35,9), tener clasificación operatoria NNIS (National Nosocomial Infection Surveillance) mayor a 2 (OR: 3,9), la presencia concomitante de neoplasia (OR: 3,1) y artroplastias previas en la articulación (OR: 2), la obesidad, el tratamiento con corticoides y la infección urinaria concomitante (5).

Etiopatogenia: La colonización de las prótesis en general requiere una baja carga bacteriana. Siendo el agente causal la misma flora cutánea, de baja virulencia. La colonización se da por dos vías principales; siembra directa durante el acto quirúrgico y por vía hematógena. Los gérmenes se adhieren a los implantes, organizándose en biocapas rodeándose de matriz extracelular glicoproteica formando el biofilm. Actuando este como medio de resistencia. Presentando una fase estacionaria en medio acido de las capas profundas, sumado a un escaso aporte de oxigeno e irrigación, razón por la cual, se presenta una tolerancia fenotípica a los antimicrobianos. Es debido a esto que se requieren concentraciones superiores a las habituales de antibióticos en el sitio de acción para obtener buena actividad. Los más afectados por este mecanismo de resistencia son los amino glucósidos, glucopéptidos y betalactámicos. $(7,19)$.

Etiología: Los cocos Gram positivos son los gérmenes más frecuentes, llegando a ser el $75 \%$ del total, el Staphylococcus coagulasa negativo representa el 35\%, Staphylococcus aureus 25\%, los bacilos Gram negativos, Pseudomonas aeruginosa y enterobacterias son el $10 \%$. Streptococcus y Enterococcus faecalis son el 10\%. De los anaerobios, Propionibacterium acnes ocupan el 5\%. En el $10 \%$ de los casos son cultivos negativos. En las IPP y IHA
Staphylococcus aureus y los bacilos Gram negativos son los gérmenes más frecuentes. En las ICT y en CIOP se encuentran gérmenes de baja virulencia, como Staphylococcus coagulasa negativo y Propionibacterium (7).

Tratamiento: El objetivo principal en el tratamiento de la infección por TKA es erradicar la infección. El manejo del dolor y la recuperación de la función son objetivos secundarios, pero no menos importantes. A través de la influencia de la literatura estadounidense, el desbridamiento con retención $(D+R)$ y el reemplazo en un único procedimiento (1T) se usan con menos frecuencia. Además, la colocación temporal de un espaciador que contiene antibióticos, seguido por sustitución con el implante definitivo (2T) y la terapia de supresión (ST), también ha sido propuesto. Segawa et al. Definió cuatro fases clínicas de la infección por ATR que son útiles para guiar el tratamiento: I - infección identificada en el momento del procedimiento; II infección postoperatoria aguda; III - identificación algunos años después del procedimiento original, proveniente de un enfoque distante; IV - infección crónica $(12,13,15)$

\section{Tratamiento médico:}

\section{Antibioterapia peri operatoria:}

Los antibióticos se utilizan de rutina para todo tipo de cirugías con implantes, incluidas las PTR. Las cefalosporinas y penicilinas semisintéticas son la primera elección por su actividad contra los gérmenes más comunes, Gram positivos (estafilococo y estreptococo), sin embargo los Gram negativos, anaerobios, bacilos ácido-alcohol resistentes y hongos, a veces pueden causar infecciones profundas. En caso de pacientes alérgicos a la penicilina o a las cefalosporinas, se puede utilizar Vancomicina, pero podría presentar efectos secundarios, como rash cutáneos, nefro toxicidad e hipotensión. El método de aplicación actual es dar peri operatoriamente el antibiótico de elección, 30 minutos antes de la incisión cutánea y continuar durante 24-48 horas dependiendo de cuándo se retira el drenaje (11, 19).

\section{Supresión antibiótica:}

Hay pocas indicaciones y los criterios para su aplicación son cuando los componentes protésicos están firmemente anclados, los tejidos circundantes y la piel, intactos. Cualquier lesión y/o criterio de infección contraindica su aplicación, puede ser la única alternativa para suprimir la infección en un paciente en mal estado general, cuando el riesgo de una cirugía es mayor al beneficio, el germen debe ser poco virulento, sensible para terapia oral, de baja toxicidad a largo plazo. Estos pacientes no deben tener otros implantes protésicos, por el riesgo de colonización hematógena y afectación de la misma. Como desventaja tiene la selección de cepas resistentes y el aflojamiento doloroso de la prótesis. Sólo el $20 \%$ de los casos así tratados buena evolución a medio plazo $(11,14,15)$. 


\section{Tratamiento antibiótico:}

Se inicia durante el procedimiento de la primera etapa y, generalmente, se continúa por cuatro a seis semanas después de la cirugía según lo recomendado por IDSA y el Consenso Internacional sobre Infección de Prótesis de Rodilla. Tratamiento endovenoso en las primeras dos semanas, luego tratamiento oral según perfil de resistencia de germen (14).

Actualmente, no hay criterios para determinar la segunda etapa. La mayoría de los cirujanos permiten un período de dos semanas sin antibióticos antes de esta, sin embargo, no hay evidencia que respalde esto. Los niveles de VSG y PCR se pueden medir antes de la segunda etapa. Sin embargo, pueden ser variables y no son representativos del control en la infección, tampoco predicen un fracaso posterior, se sugiere realizar una aspiración de la rodilla antes de la segunda etapa, debido a que ha demostrado ser específico (92\% a $100 \%)$ pero la sensibilidad es inconsistente (0\% a 100\%). Para minimizar la tasa de cultivos falsos negativos, la aspiración se debe realizar dos semanas después de finalizar los antibióticos sistémicos. No se sabe el punto de corte citológico ni porcentaje de neutrófilos en pacientes con espaciador $(20,21)$.

\section{Tratamiento quirúrgico: \\ Irrigación y desbridamiento:}

El desbridamiento y el riego agresivos con intercambio del revestimiento de polietileno solo deben realizarse en pacientes con un IPP. No debe usarse en pacientes con factores de riesgo de infección persistente o recurrente, como aquellos con tejidos blandos locales pobres, aquellos con compromiso inmunitario y aquellos con patógenos resistentes debido a los riesgos de colonización persistente e infección poli microbiana (15). Un desbridamiento agresivo de los tejidos peri articulares y los componentes debe llevarse a cabo para reducir la carga bacteriana y mejorar la eficiencia del sistema inmune del paciente y los antibióticos contra los gérmenes residuales. Por lo que tejidos blandos y óseos que no sangran deben eliminarse. El inserto debe ser retirado y preferiblemente intercambiado, tomando muestras y desbridando la capsula posterior. Explorar los componentes en busca de aflojamiento (16).

Hay protocolos que sugieren irrigación con nueve litros, aunque no hay protocolo que ofrece mejor resultado, el lavado a baja presión (<15 libras por pulgada cuadrada) o alta presión (> 45 libras por pulgada cuadrada) aún no tiene beneficios establecidos entre ambos. El lavado a alta presión brinda una eliminación rápida y efectiva de tejidos necróticos, pero puede dañar los tejidos y favorecer la penetración de gérmenes a tejidos profundos (16).

Algunos autores sugieren el desbridamiento, tratamiento con antibióticos más de un año y retención de implantes (DAIR) para el tratamiento del IPP. Sin embargo, hay riesgo de recurrencia posterior a la suspensión de la terapia antibiótica $(18,19)$.

\section{Artroplastia de intercambio en una etapa:}

Tiene muchas ventajas, este tratamiento se realiza hasta en un $85 \%$ en centros especializados en Europa y está ganando seguidores en América del Norte. Es una opción viable para la mayoría de los pacientes con un IPP. El germen y sensibilidad debes conocerse antes de la cirugía, lo que permite el uso de cemento con antibiótico $(18,20)$.

No debería realizarse el procedimiento en los siguientes casos:

- Sepsis con manifestaciones sistémicas sustanciales (shock y/o descompensación).

- Fallo de dos o más procedimientos anteriores de una etapa.

- Infección que involucra los componentes neuro vasculares, que impide el desbridamiento radical.

- IPP con cultivo negativo, y no tener tratamiento antibiótico apropiado.

- Daño de partes blandas extenso que no permita el cierra de primera intención.

- Infección con un germen altamente agresivo, especialmente si los antibióticos apropiados para la adición al cemento no están disponibles $(16,20)$.

\section{Artroplastia de intercambio en dos etapas:}

En pacientes con ICT, se recomienda el intercambio en dos etapas, que implica la eliminación de todo el material, incluido el cemento, y el desbridamiento agresivo de los tejidos blandos y el hueso en la primera etapa. Se coloca un espaciador de preferencia con antibiótico y se administran antibióticos sistémicos entre cuatro y seis semanas. Posteriormente cuando se considera que la rodilla está libre de infección, se lleva a cabo la segunda etapa para introducir nuevos componentes. Sin embargo, si hay alguna sospecha de infección persistente, se debe realizar un desbridamiento repetido con intercambio del espaciador $(14,15,18,20)$. El desbridamiento muy extenso es esencial para los procedimientos de una y dos etapas. Si bien es obligatorio eliminar todos los componentes (femoral, tibial y patelar, cemento óseo, restrictores de cemento, tornillos y alambres), en un procedimiento de dos etapas, también se requiere un desbridamiento meticuloso. Se debe tener especial cuidado para desbridar la cápsula posterior, ya que podría ser la fuente de la reinfección $(14,16,20)$.

Se debe tratar de preservar el máximo tejido óseo, por ejemplo usar cierras oscilantes y osteótomos, pudiendo ser menos destructivo que la extracción agresiva usando un mazo y dispositivos convencionales de extracción. El desbridamiento general del hueso y los tejidos blandos posteriores debe ser lo más radical posible, incluidas todas las áreas de osteólisis y hueso necrótico $(14,15,16$, $17,18)$.

\section{Reimplantación:}

Se realiza cuando la herida está cicatrizada, la rodilla está clínicamente (y / o por parámetros de laboratorio) lista para una nueva cirugía, libre de proceso infeccioso y el paciente está en condiciones óptimas para una cirugía. Sin embargo, no hay pruebas óptimas para determinar al momento óptimo. Generalmente se realiza después de dos o tres meses de la primera etapa. Durante el 
procedimiento, se administran más antibióticos y se realiza un desbridamiento más agresivo. El preferible realizar una sinovectomía anterior, sinovectomía posterior $(20,21)$.

La cementación permite la administración de antibióticos, mientras que los tallos diafisarios que no se cementan pueden mejorar la alineación y la facilidad de extracción si hay una reinfección. También se han descrito técnicas híbridas usando tallos no cementados que se relacionan con la diáfisis en los componentes femoral y tibial. El cemento se aplica a la superficie inferior de los componentes en la metáfisis. Sin embargo, la evidencia disponible muestra que la tasa de reinfección es similar con diferentes tipos de fijación, según un estudio comparativo (20\% frente a $24 \%$ para componentes cementados e híbridos, respectivamente) y varios estudios no comparativos (8). \% a $14 \%$ para componentes cementados y $6 \%$ a $17 \%$ para componentes no cementados e híbridos $(19,20,21)$.

El procedimiento de la segunda etapa debe verse como otra oportunidad para realizar un desbridamiento agresivo. Los antibióticos postoperatorios se continúan hasta que estén disponibles los resultados microbiológicos de los cultivos intra operatorios. Si estos cultivos son positivos, se debe considerar el tratamiento prolongado con antibióticos $(14,17,20,21)$.

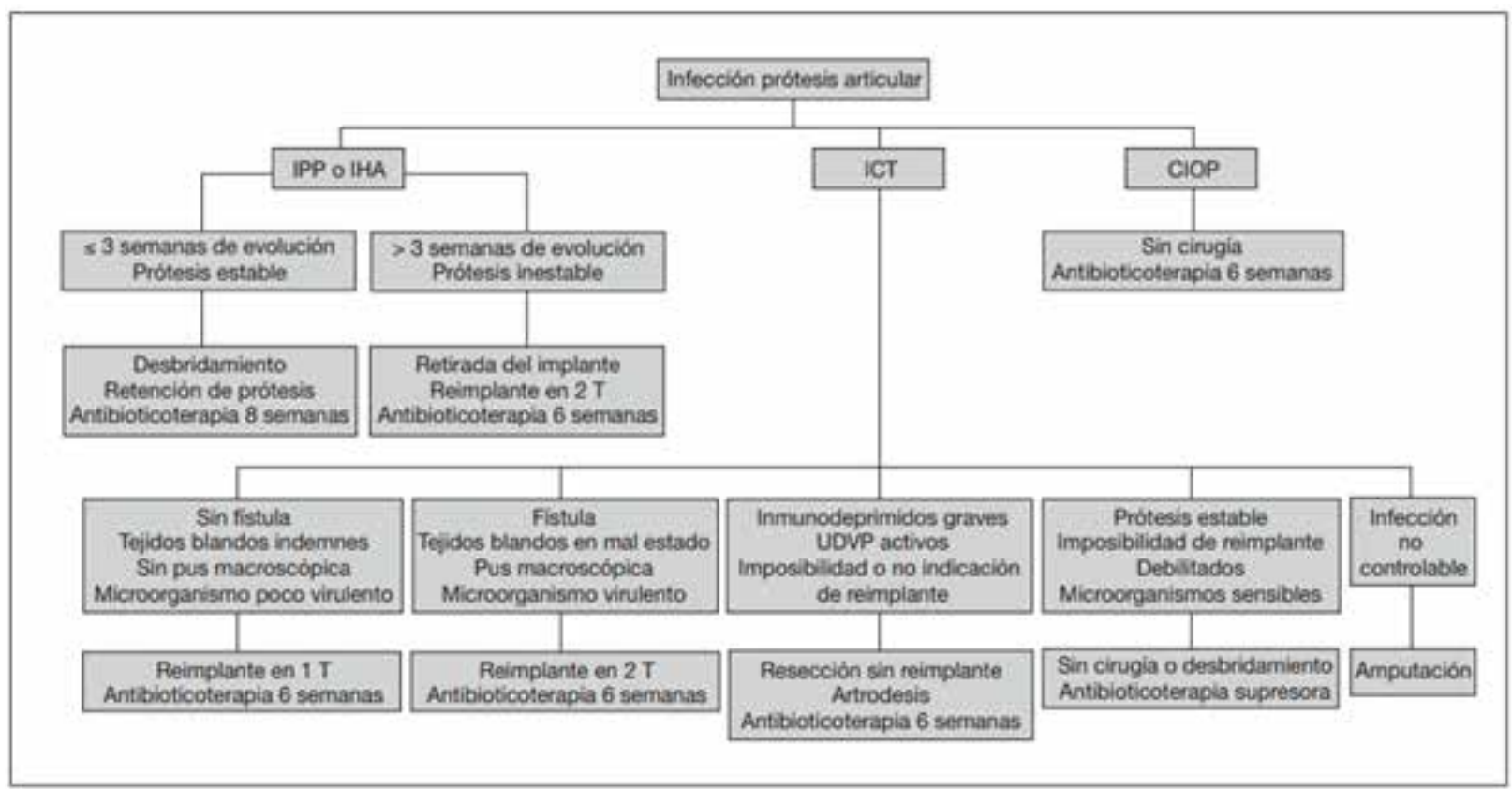

Algoritmo de tratamiento.

Recuperado de: Javier Ariza, Gorane Euba y Óscar Murillo "Infecciones relacionadas con las prótesis articulares" Enferm Infecc Microbiol Clin 2008; 26(6):380-90 Pág. 387.

\section{CONCLUSIÓN}

La artroplastia total de rodilla es el procedimiento quirúrgico con la mejor tasa de éxitos, produciendo gran mejoría a los pacientes que se benefician de esta.

La evolución de los implantes, profilaxis antibiótica, procedimientos quirúrgicos seguros, hacen que la tasa de complicaciones sea baja.

El diagnóstico y tipificación de cada presentación clínica, supone un reto para el médico, siendo esto crucial para un adecuado y oportuno manejo, de lo cual depende el pronóstico y evolución de cada paciente.

Es importante un tratamiento médico y quirúrgico agresivo, a fin de limitar la progresión de esta patología. Es importante realizar los cultivos, así como tener un mapa microbiológico con las cepas y perfil de cada agente causal a fin de brindar un tratamiento antibiótico efectivo.

El agente causal más frecuente $75 \%$ son los cocos Gram positivos.

Paciente con cirugía protésica dolorosa, es infección hasta que se demuestre lo contrario.

El factor de riesgo más importante es la presencia de
Artritis reumatoide, además de otras patologías como son: diabetes, alcoholismo, insuficiencia renal crónica, cáncer, desnutrición y enfermedades que comprometan el sistema inmune.

El objetivo principal del tratamiento es erradicar la infección.

Los objetivos secundarios del tratamiento son: manejo del dolor y recuperación de la función.

El tratamiento quirúrgico se realiza dependiendo del cuadro clínico, y pudiera ser desde una irrigación y desbridamiento, hasta una cirugía en dos tiempos con la colocación de espaciadores impregnados con antibiótico.

El tiempo óptimo para la cirugía de re implante no se ha delimitado, pero se estima entre dos a tres meses de completado el tratamiento antibiótico y en ausencia de cuadro clínico infeccioso.

La presentación de esta temida complicación supone largos periodos de estancia hospitalaria, antibiótico terapia intravenosa, menoscabo en la calidad de vida del paciente, así como un elevado costo para la entidad prestadora de servicios de salud. 


\section{REFERENCIAS BIBLIOGRÁFICAS}

1. Molko S, Combalia A. La cirugía de recuperación rápida en las artroplastias de rodilla y cadera. Una actualización. Rev Esp Cir Ortop Traumatol. 2017. http://dx.doi.org/10.1016/j.recot.2017.01.002.

2. Rodríguez-Merchán, E. C., \& García-Tovar, O. I. (2009). La prótesis total de rodilla inestable. Revista Española de Cirugía Ortopédica y Traumatología, 53(2), 113-119. doi:10.1016/j.recot.2008.09.003.

3. Risks and Complications of Total Knee Replacement Surgery, William Morrison, MD on October 23, 2017 https://www.healthline.com/health/total-knee-replac ement-surgery/risks-complications\# 1.

4. Knee replacement infection: What you need to know Last reviewed Fri 5 January 2018 By Lana Burgess Reviewed by William Morrison, MD https://www.medicalnewstoday.com/articles/320519. php.

5. Javier Ariza, Gorane Euba y Óscar Murillo "Infecciones relacionadas con las prótesis articulares" Enferm Infecc Microbiol Clin 2008;26(6):380-90.

6. T. Gehrke P. Alijanipour J. Parviz The management of an infected total knee arthroplasty Bone Joint J 2015; 97-B (10 Suppl A): 20-9.

7. Dra. Karina Tenaglia Infección de prótesis articulares http://www.infectologia.edu.uy Abril de 2013.

8. Lúcio Honório de Carvalho Júnior, Infection after total knee replacement: diagnosis and treatmentActa Ortop Bras . 2015 de septiembre a octubre; 23 (5): 239 $-243$.

9. Julián Palomino Nicás (coordinador)1, Andrés Puente González2, Macarena López Pliego2, Julio Valencia Anguita3, Clara Aguilera Cros2, LuisE. López Cortés1, Manuel E. Jiménez Mejías1.Infección de prótesis articular 15 diciembre, 2017.

10. Javad Parvizi, MD The 2018 Definition of Periprosthetic Hip and Knee Infection: An Evidence-Based and Validated Criteria The Journal of Arthroplasty 33 (2018) 1309e1314.

11. MANFREDA F1, ANTINOLFI P2, PETRUCCELLI R1 , PALMIERI D1, TEODORI J1, RICCHIUTO I1,
RINONAPOLI G1,2 AND CARAFFA A1,2 New trends for diagnosis and treatment of infected total knee arthroplasty J ORTHOP TRAUMA SURG REL RES 12(2) 2017.

12. Mervyn J Cross, MBBS, FRACS, MD Complications of Total Knee Arthroplasty Updated: Feb 05, 2018.

13. Niraj V Kalore,1 Terence J Gioe, 1 and Jasvinder A Singh Diagnosis and Management of Infected Total Knee Arthroplasty Open Orthop J. 2011; 5: 86-91.

14. Chul-Won Ha, MD Treatment of Infected Total Knee Arthroplasty, Knee Surg Relat Res. 2017 Sep; 29(3): 153-154.

15. Pouya Alijanipour and Javad Parvizi Infection post-total knee replacement: current concepts Curr Rev Musculoskelet Med. 2014 Jun; 7(2): 96-102.

16. G. Bori a, E.L. Gómez-Durán Seguridad clínica y reclamaciones por responsabilidad profesional en Cirugía Ortopédica y Traumatología Rev Esp Cir Ortop Traumatol. 2016;60(2):89-98.

17. Insall J.N., Thompson F.M., Brause B.D.: Two-stage reimplantation for the salvage of infected total knee arthroplasty. J Bone Joint Surg Am. 1983; 65(8): 1087-1098.

18. Springer B.D.: The Diagnosis of Periprosthetic Joint Infection. J Arthroplasty. 2015; 30(6): 908-911.

19. Della Valle C., Parvizi J., Bauer T.W., et al.: American Academy of Orthopaedic Surgeons. American Academy of Orthopaedic Surgeons clinical practice guideline on: the diagnosis of periprosthetic joint infections of the hip and knee. J Bone Joint Surg Am. 2011; 93(14): 1355-1357.

20. Renz N., Perka C., Trampuz A.: Management of periprosthetic infections of the knee. Orthopedics. 2016; 45(1): 65-71.

21. Robinson, Matthew, MD Knee Arthrodesis Outcomes After Infected Total Knee Arthroplasty and Failure of Two-stage Revision With an Antibiotic Cement Spacer JAAOS Global Research \& Reviews: January 2018 - Volume 2 - Issue 1 - p e077 doi: 10.5435/JAAOSGlobal-D-17-00077.

\section{PANACEA}
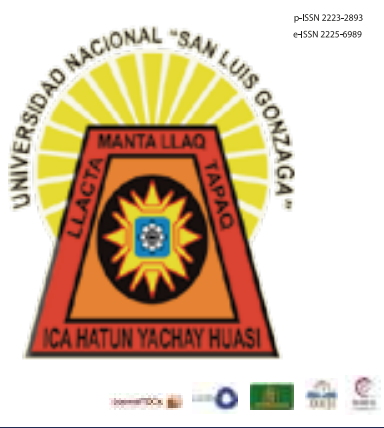